'THURSDAY, OCTOBER 5, I876

\section{THE WOUNDED IN SHOOTING}

COME time since a well-known public writer excited the surprise and anger of a large portion of the community by vehemently protesting against the amount of animal suffering caused by field-sports, and a long and rather bitter controversy ensued. Mr. Freeman's remarks were, if we recollect right, limited to "hunting," in the conventional sense of the word-that is, the chase of the fox or the hare with hounds, and many estimable persons were not a little shocked to find themselves accused of having, nearly all their life-time, been committing the grossest cruelty. Whether the principles and practice of humanity sustained any benefit by this fierce attack, whether the attack was made in the best possible taste, and whether in making it Mr. Freeman did not overlook a very important consideration (of which, by the way, we are not aware that any of his opponents took advantage), are questions we do not here propose to discuss. We are now led to make a few calculations based on the returns contained in the Eighteenth and last Report of the Board of Inland Revenue of the number of persons who take out licences to kill what the law calls "game" and to carry a gun. This Report (which we may observe is one presented to both Houses of Parliament, and can be obtained by anybody at her Majesty's Stationery Ofice for the small sum of sixpence) is undated, but refers to the financial years $1873-4$, and 1874-5. That for the past year $(1875-6)$ is not, we believe, published, or we would gladly avail ourselves of it. However, in the Report before us it stands that, in the year $1873-4$, there were, 132,036 holders of gun licences and 65,846 holders of licences to kill game. In the year $1874-5$ the corresponding numbers were 144,278 and 68,079 . It would not be easy to estimate the number of "head" slain by these persons, but there is no reason why, for our present purpose, we should attempt to do so. The beast or bird killed by the gun generally dies as speedy a death as can possibly be inflicted, and the tenderest and most sentimental of hearts cannot complain on the score of humanity quoad the victim. But how about the wounded--which everyone knows to be many? Is it possible to estimate their number? We think it is ; but let us premise that in malking the computation we have no desire to harrow the feelings of our readers by a sensational description of the miseries which an animal may suffer from the lodging of one or many pellets of shot in any part of its body. In some cases they may be frightful, in others productive only of a slight degree of pain, hardly amounting to more than personal inconvenience; but in striking the balance we may, on the whole, assume that acute pain, enduring for some hours or days, is suffered by every beast or bird which the shot strikes, and the shooter does not "bag." Now as to the number of these wounded.

Recalling our own shooting days, we should say that a man must be an uncommonly good and careful shot who does not on an average wound without "bagging" more than three head of game each day that he takes the field. Many men will "lose" that number every day, and by "losing" a bird, a hare, or a rabbit, we mean that it has fallen to the gun or been hit hard enough to insure its capture, had not the retriever, the scent, or the marking been bad. But such cases bear no proportion to the numbers (of grouse or partridges especially) that are hit but not hard enough to be counted "lost." They are seen to flinch as they are struck, but that is all; away they go, whether to the next hill-side, into the next field, or much further, no one asks, and no one thinks more about them. A la guerre comme dे la guerre. Now supposing that all who shoot game are good and careful shots, we should have on our estimate each shooter wounding his three head per diem irrespective of what he brings to bag. But all shots are neither good nor careful, therefore we think our estimate cannot be too great, and we have also to take in cases of what may be called extravagant shooting, where the numbers of wounded must transcend any ordinary computation. ${ }^{1}$

We have now to reckon the number of days that each holder of a game licence may be supposed to shoot. The shooting season begins for grouse on August 12, for partridges on September $I$, and for pheasants on October $I$. As we do not wish to be guilty of any exaggeration, but only to strike a fair average, let us take the partridgeshooting season, i.e., from September I to February I, inclusive. $^{2}$ Herein we have twenty-one weeks. It does not seem an immoderate assumption to suppose that each holder of a licence to kill game goes out on an average two days a week during that time. There are, no doubt, many men who get no more than two days' shooting throughout the whole season and yet take out a licence; but there must be at least as many, if not more, who are not so conscientious and run the risk of shooting for the whole season without paying the duty. The Commissioners in this very Report say (p. 18 ) of the Game Licence, that "while it is used by game preservers as a means of punishing poachers, there can be no doubt that among persons of a higher station in life it is very largely evaded." Then there is a very considerable number of inveterate sports men who go out day after day throughout the whole season-to say nothing of the grouse shooters who, as most of them pay highly for their moors, unques. tionably shoot every day they can for a month or six weeks. Therefore taking the partridge season as a basis, we think that our assumption of an average of two days a week for those twenty-one weeks is not excessive This will give an average of forty-two days of shooting for each of the 65,846 holders of licences to kill game in 1873-4, and of the 68,079 in 1874-5. Now we have already shown the likelihood that each of them wounds on an average three head of game per diem, we therefore multiply both of these numbers by $126(=42 \times 3)$ and we find that in the former of these two years there must I One such very recent case we may cite from the columns of a contemporary (The Field, Sept. 23, 1876). In nine days, between the rst and ist of September, inclusive, of this year, the Maharajah Duleep Singh, on his estate at and near Elveden, killed to his own gun 2689 head of game, of which $253^{\circ}$ were partridges. This is vouched for by his Highness's headgamekeeper. It is true that there is only one Elveden and one Maharajah in this country, and that the fact of its being communicated to a newspaper shows that both master and man thought the slaughter rather remarkable but instances which approach it are not altogether unknown.

${ }_{2}$ The Report on which we base our calculations is in one respect defective, since it does not separate the respeciive numbers of holders of licences for the entire year or for the half-year. Judging, however, from the amounts of duty charged, the latter are about one-fifth of the whole. The majority of them are supposed to be chiefly sehoolboys, and, as they are learning the art, they may be justly considered clumsy performers with the gun, wounding more than the average of adult shots. 
have been $8,296,496$, and in the latter $8,577,954$ animals left wounded.

Then with regard to the holders of gun licences. It does not seem an excessive estimate to suppose that each wounds on an average two animals (birds, almost exclusively, in this case) a week throughout the year of fifty-two weeks. A great proportion of holders of these licences no doubt do not exercise their privilege every week. Many of them do so only with the object of protecting their crops; but the season for fruit and garden vegetables goes on all the summer, say from May to September, and the harvest lasts six weeks, while for some three weeks before that begins the corn is ripening, and is then most attractive to sparrows. A single shot into a flock of sparrows will wound many more than it kills, and such shots, as our ears tell us, are frequent during the day. It does not seem possible to place the average number of birds wounded by each holder of a gun licence lower than we have done. We have therefore to multiply the number of holders by I04 $(=52 \times 2)$, and then we find that in 1873-4 there must have been $13,731,744$, and in 1874-5, $15,004,912$ animals left wounded by this class of persons.

Adding the two sets of numbers, we have a grand total for the former of these years, $22,028,240$, and for the latter, 23,582,866 wounded; while this increase of over $\mathrm{I}, 500,000$ in one twelvemonth forbids our supposing that the next Report would show much, if any, diminution.

Just as before we purposely abstained from distressing our readers by dwelling on the effects of all this wounding, so now we purposely abstain from using any strong language, or calling those who shoot by bad names. This is not meant to be a sensational article. We are sure in our own mind that sportsmen are not by nature cruelvery far from it. Yet, if we may trust our figures, here are the plain facts that acute pain of uncertain duration was, in the year ending March 3r, 1874, inflicted upon over twenty-two millions of animals, and in the following year upon over twenty-three millions and a half in the British Islands. We are not aware that we possess any bias that would make us exaggerate our estimates to produce these results. Our only object is to attempt as near an approximation to the truth as we can. The figures stand for themselves, and if anyone thinks he can furnish fairer averages let him give his data for them. We are, as it is, willing to guard against any unconscious exaggeration and to knock off more than Io per cent. of our grand totals, so as to say roundly that only twenty millions have suffered in each year. But we would invite our readers to reflect on the proportion which even that number bears to the number of animals which during the same time have been subjected to experiment by the physiologists of this country. The latter have been by many excellent persons held up to obloquy as monsters of cruelty. If this has been done justly what must they think of those who use the gun?

\section{BLASERNA ON MUSICAL SOUND}

The Theory of Sound in its Relation to Music. By Prof.

Pietro Blaserna, of the Royal University of Rome.

With Numerous Woodcuts. International Scientific Series. (London : Henry S. King \& Co., I 876.)

$\mathrm{F}^{\mathrm{F}}$ the many valuable works which have appeared in the International Scientific Series, none deal with a better subject than that of Prof. Blaserna. "The student of physics," he says truly in his Preface, "does not go much into the study of musical arguments, and our artists do not sufficiently understand the very important bearing that the laws of sound have upon many musical questions."

The first three chapters of the book hardly call for detailed notice. They reproduce the familiar facts of acoustics lucidly and succinctly. Vibration, its transmission and velocity, echo, noise as contrasted with musical sound reinforcement by sympathy, sounding-boards and resonators, complete the first division of the subject. The second begins with measurements of vibration, graphically or by means of the siren. The limits of audible sounds are thus determined to lie between 16 and 38,000 per second; of the human voice between the 6 I vibrations of double $B$ is the bass, and the 1,305 of the soprano $F$ in alt.

The importance of uniform pitch is adverted to. Its invariable rise, in the course of years, is explained by the "tendency of manufacturers of musical instruments, especially those made of brass, to raise the pitch continually, in order to give a greater brilliancy of tone to their instruments ;" an indictment in which the players might justly have been included as well as the manufacturers.

The harmonic series, and its demonstration by means of the sonometer, conclude the fourth chapter. The laws of ratios, of interference, and of beats, with their resultant notes, occupy the fifth. From these the ancient Greek scale, attributed to Pythagoras, is built up, and compared with our modern. scale, the youngest nember of which, the minor third, "was only adopted in the seventeenth century, with many reservations, together with the harmony of the sixth, from which it can be easily derived."

Of the harmonic seventh (rather awkwardly termed throughout "the seventh harmonic") it is judiciousiy observed that "to an ear accustomed to our music, it may appear unpleasant; but an unprejudiced examination, according to the opinion of some-an opinion with which I entirely agree-shows that it is rather strange than unpleasant; that in certain special cases it affords very good discords and passing chords, and that the strangeness arises rather from our want of familiarity with it than from its inherent nature. Without wishing to push too far forward, and to prophecy what will happen in the future, it may be observed that the systematic introduction of the harmonic seventh into music would produce in it a very deep and almost incalculable revolution, a revolution which does not seem justifiable, because, for our magnificent musical system, another would be substituted, perhaps as magnificent, but certainly not better, and probably worse, at any rate more artificial."

Helmholtz's double siren is described at some length, and illustrated by numerical examples, carrying the student on to chords of three or more notes; the marked difference in character between the major and minor common chords being attributed to the disturbing effect of the resultant notes in the latter, which is absent in the former. Even Mozart shows "a certain reluctance to use the minor as a closing chord. It may be that the most highly gifted musical natures have, as it were, felt beforehand that which theory has since been able to explain in a simple and conclusive way." Discords and their contrast with concordant intervals lead to a comparison of music 